\title{
Combined first trimester screen or noninvasive prenatal testing or both
}

Tony Yew Teck Tan, FRCOG, FAMS

\section{INTRODUCTION}

In Singapore, Down syndrome screening is routinely offered to all pregnant women regardless of age. ${ }^{(1)}$ The most common test offered is the combined first trimester screen (FTS) if the patient presents before 14 weeks of gestation. The combined FTS comprises detailed ultrasonography (USG) measuring the crown rump length (CRL) and the nuchal translucency (NT) of the fetus at 11-13 weeks of gestation, combined with serum screening of free beta-human chorionic gonadotrophin (bhCG) and pregnancyassociated plasma protein A (PAPP-A) at between 8-13 weeks of gestation. While the combined FTS detection rate of $90 \%$ is excellent, the main problem is its relatively high false positive rate, where 1 in 20 (5\%) patients screened would be unnecessarily worried. ${ }^{(2)}$ Another problem is ensuring the quality of the USG component due to the operator-dependent nature of USG. Hence, good USG machines are required, and well-trained sonographers need to be accredited and regularly audited, to avoid potential disputes when Down syndrome cases are missed.

Noninvasive prenatal testing (NIPT) via the analysis of cell-free fetal DNA (cffDNA) from the plasma of pregnant women has recently become commercially available. There are many companies now that offer this test with different patented algorithms. These screening tests have demonstrated detections rates $>98 \%$ for Down syndrome (trisomy 21) and Edward syndrome (trisomy 18), and $>90 \%$ for Patau syndrome (trisomy 13 ), with very low false positive rates of $0.1 \%-0.5 \%$ in high-risk populations (i.e. those who have been screened positive by advanced maternal age, past or family history, combined FTS, second trimester serum screening or second trimester USG), ${ }^{(3-7)}$ which reduces unnecessary worry and the need for invasive prenatal procedures such as chorionic villus sampling (CVS) or amniocentesis in patients. Indeed, various guidelines, including the December 2012 guideline of the American College of Obstetricians and Gynecologists, state that NIPT should not be offered to low-risk women or women with multiple gestations, in view of the limited data in these groups at the time. ${ }^{(8)}$ As more data showing very high detection rates for Down syndrome is being accumulated for low-risk women ${ }^{(9-11)}$ and multiple gestations, ${ }^{(12)}$ it is likely that these guidelines will change soon. Bianchi et al have demonstrated a lower false positive rate for cffDNA compared to standard screening $(0.3 \%$ vs. $3.6 \%$ ) with $100 \%$ detection rates using both methods, albeit with a limited number of Down syndrome fetuses in the study. ${ }^{(9)}$ It is important, however, to note that the positive predictive value of a positive cffDNA for fetal Down syndrome in low-risk populations is only about $45 \%$, ${ }^{(9)}$ and hence, it is critical to perform an invasive diagnostic test before termination of such fetuses, as one in two fetuses could be normal despite a positive test. This test can be taken as early as ten weeks into the pregnancy and requires one to two weeks for a result to be reported. The Achilles heel of this test is the non-report rate of $1 \%-5 \%$ for various reasons, including low fraction of the cffDNA due to early gestation or maternal characteristics such as increased body mass index. It is also very expensive at the time of writing, with the cheapest test costing just under $\$ \$ 1,000$.

Local practices pursue different strategies with regard to integrating NIPT in the Down syndrome screening protocols. Some offer NIPT to all, others offer to none, while others may offer it as a contingency test to women who are found to be at intermediate risk at FTS.

\section{DIFFERENT STRATEGIES}

The paper from National University Hospital and Singapore General Hospital by Li et al published in this issue of $S M$ J is a good example of collaborative work across healthcare clusters in Singapore. ${ }^{(13)}$ This study is an audit of the performance of combined FTS in two tertiary Obstetrics and Gynaecology centres in Singapore, and provides good local data to examine the different strategies that can be employed in Singapore. Based on a total screened population of 10,295 mentioned in the paper, the average cost of test(s) per patient (see Table I) is as follows:

a) Least cost: with the strategy of performing FTS on all, with CVS or amniocentesis offered to those with risk $\geq 1: 250$ at the time of screening (about S\$342).

b) Marginally higher cost: with the strategy of performing FTS on all, with CVS or amniocentesis offered to those with risk $\geq 1: 100$, NIPT to those with risk of $1: 101$ to $1: 1,000$, and CVS or amniocentesis performed for those screened positive via NIPT (about S\$407).

c) Highest cost: with the strategy of performing NIPT on all, with CVS or amniocentesis offered to those who are screened positive (about $\$ \$ 1,011$ ).

\section{Combined FTS for all}

This strategy still offers the most cost-effective method for the detection of trisomy 21/18/13 fetuses, though it missed six cases in the aforementioned study population. ${ }^{(13)}$ On top of that, some centres also offer screening for structural abnormalities, early onset preeclampsia and preterm intrauterine growth restriction at the same time as FTS examination, which could be accomplished by a quick structural survey, measurement of the mean arterial 
Table I. Comparison of the different strategies of screening in a population of 10,295 pregnant women in Li et al's study.(13)

\begin{tabular}{lcccccc}
\hline Strategy & $\begin{array}{c}\text { Total cost of screening } \\
\text { over } \mathbf{6} \text { years } \\
\text { (S\$) (a) }\end{array}$ & $\begin{array}{c}\text { No. of } \\
\text { screened } \\
\text { positive cases } \\
\text { (b) }\end{array}$ & $\begin{array}{c}\text { Cost of CVS/ } \\
\text { amniocentesis for } \\
\text { screened positive } \\
\text { cases (S\$) (c) }\end{array}$ & $\begin{array}{c}\text { Total } \\
\text { costs = (a) + (c) }\end{array}$ & $\begin{array}{c}\text { No. of } \\
\text { T21/T18/ } \\
\text { T13 cases } \\
\text { detected }\end{array}$ & $\begin{array}{c}\text { Average cost } \\
\text { per patient } \\
\text { (S\$) }\end{array}$ \\
\hline FTS for all & $3,088,500$ & 288 & 432,000 & $3,520,500$ & 43 & 342 \\
NIPT for all & $10,295,000$ & $49+31=80$ & 120,000 & $10,415,000$ & 49 & 1,011 \\
$\begin{array}{l}\text { FTS for all and NIPT } \\
\text { for patients with risk } \\
\text { of 1:101 to 1:1,000 }\end{array}$ & $3,088,500+666,000=3,921,500$ & $167+13=180$ & 270,000 & $4,191,500$ & 47 & 407 \\
\hline
\end{tabular}

Assumptions for NIPT: there is $100 \%$ detection rate for T21, T18 and T13, with a $0.3 \%$ false positive rate; cost is S $\$ 300$ per combined FTS, S $\$ 1,000$ per NIPT and S $\$ 1,500$ per CVS or amniocentesis. CVS: chorionic villus sampling; FTS: first trimester screening; NIPT: noninvasive prenatal testing; T: trisomy

pressure, and Doppler measurement of the mean uterine artery pulsatility index (PI) by an accredited sonographer.

While the second trimester uterine artery PI yields better detection rates for preeclampsia and intrauterine growth restriction than that of the first trimester uterine artery $\mathrm{PI}$, assessing the risk at first trimester allows low-dose aspirin of 100-150 mg to be started before 16 weeks. Starting low-dose aspirin before 16 weeks has been shown to reduce preeclampsia, severe preeclampsia, intrauterine growth restriction, perinatal death and preterm birth when compared to introduction after 16 weeks, ${ }^{(14)}$ and especially if aspirin is taken at bedtime. ${ }^{(15)}$

\section{NIPT for all}

In a study of FTS combined screening, where 1,831 clinically significant chromosomal abnormalities were detected via CVS for a combined risk of trisomies 21, 18 and $13 \geq 1: 100$, $83 \%$ were trisomies 21,18 or $13,8 \%$ were sex chromosome aneuploidies, $4 \%$ were triploidy and $5 \%$ were other chromosomal abnormalities. ${ }^{(16)}$

Hence, the following are the main disadvantages of NIPT:

1. High cost for the detection of each case of trisomy 21, 18 or 13. The average cost for the test(s) would be significantly lower at $\mathbf{\$ 5} 512$ per patient if the cost of NIPT were $S \$ 500$ each. This would certainly make it more acceptable for clinicians to implement NIPT as a routine test, to be offered at the population level.

2. Missing up to $10 \%$ of other atypical chromosomal abnormalities, including triploidy and chromosomal abnormalities other than trisomies 21, 18 and 13 . These cases would otherwise have been detected via combined FTS.

3. Up to $5 \%$ chance of failure to obtain a result at the first instance. Therefore, it may be better to offer NIPT at ten weeks of gestation. If NIPT does not yield a result within two weeks, there is still an option to perform combined FTS by $12-13$ weeks of gestation.

4. Unable to screen for severe structural abnormalities, early onset preeclampsia and preterm intrauterine growth restriction in the first trimester.

\section{FTS for all and contingency testing with NIPT for intermediate group}

This strategy allows for a very cost-effective method for detection of trisomy 21, 18 or 13 fetuses, with a marginally increased cost per patient, but a $40 \%$ reduction in the proportion of screened positive cases (and hence reduction in invasive diagnostic procedures) compared to the first strategy. This strategy missed two cases in this screened population. ${ }^{(13)}$ It also enables the screening of atypical chromosomal abnormalities that present with grossly increased nuchal translucency. For centres that have already implemented the additional screening protocol at FTS, this strategy also allows for screening of early onset preeclampsia and preterm intrauterine growth restriction, so that intervention with low-dose aspirin before 16 weeks (which would not have been possible with the second strategy) can be implemented.

\section{CONCLUSION}

At the population level, offering combined FTS for all and contingency testing with NIPT for those screened to have a risk of $1: 101$ to $1: 1,000$ is cost-effective and seems to be the ideal strategy currently. At the individual level, patients should be told about the availability of NIPT as an alternative but expensive screening method with a better detection rate and a lower false positive rate. If the patient chooses to have NIPT, FTS (without free bhCG and PAPP-A) may still be offered, as it allows detection of some atypical chromosomal and structural abnormalities, especially more so in centres where the FTS programme incorporates screening for early onset preeclampsia and preterm intrauterine growth restriction. This will enable low-dose aspirin to be offered as an early intervention.

\section{REFERENCES}

1. College of Obstetricians and Gynaecologists, Singapore. Recommended 'Best Practice' Guidelines on Antenatal Screening for trisomy 21 (Down syndrome) and other Fetal Aneuploidies. January 2008

2. Nicolaides KH. Screening for fetal aneuploidies at 11 to 13 weeks. Prenat Diagn 2011; 31:7-15.

3. Chiu RW, Akolekar R, Zheng YW, et al. Non-invasive prenatal assessment of trisomy 21 by multiplexed maternal plasma DNA sequencing: large scale validity study. BMJ 2011; 342:c7401.

4. Ehrich M, Deciu C, Zwiefelhofer T, et al. Noninvasive detection of fetal trisomy 21 by sequencing of DNA in maternal blood: a study in a clinical setting. Am J Obstet Gynecol 2011; 204:205.e1-11.

5. Sparks AB, Wang ET, Struble CA, et al. Selective analysis of cell-free DNA in maternal blood for evaluation of fetal trisomy. Prenat Diagn 2012; 32:3-9.

6. Palomaki GE, Kloza EM, Lambert-Messerlian GM, et al. DNA sequencing of maternal plasma to detect Down syndrome: an international clinical validation study. Genet Med 2011; 13:913-20.

7. Bianchi DW, Platt LD, Goldberg JD, et al; MatErnal Blood IS Source to Accurately diagnose fetal aneuploidy (MELISSA) Study Group. Genomewide fetal aneuploidy detection by maternal plasma DNA sequencing. Obstet Gynecol 2012; 119:890-901. 
8. The American College of Obstetricians and Gynecologists and the Society for Maternal-Fetal Medicine. Committee Opinion on Noninvasive Prenatal Testing for Fetal Aneuploidy. Number 545, December 2012

9. Bianchi DW, Parker RL, Wentworth J, et al; Care Study Group. DNA sequencing versus standard prenatal aneuploidy screening. N Engl J Med 2014; 370:799-808.

10. Lau TK, Cheung SW, Lo PS, et al. Non-invasive prenatal testing for feta chromosomal abnormalities by low-coverage whole genome sequencing of maternal plasma DNA: review of 1982 consecutive cases in a single center. Ultrasound Obstet Gynecol 2014; 43:254-64.

11. Liao C, Yin AH, Peng CF, et al. Noninvasive prenatal diagnosis of common aneuploidies by semiconductor sequencing. Proc Natl Acad Sci USA 2014 111:7415-20.

12. Bevilacqua E, Gil MM, Nicolaides KH, et al. Performance of screening for aneuploidies by cell-free DNA analysis of maternal blood in twin pregnancies. Ultrasound Obstet Gynecol 2014 Oct 9. doi: 10.1002/ uog.14690. [Epub ahead of print].

13. Li WS, Barrett AN, Gole L, et al. The assessment of combined first trimester screening in women of advanced maternal age in an Asian cohort. Singapore Med J 2015: 56:47-52.

14. Roberge S, Nicolaides KH, Demers S, Villa P, Bujold E. Prevention of perinatal death and adverse perinatal outcome using low-dose aspirin: a meta-analysis. Ultrasound Obstet Gynecol 2013; 41:491-9.

15. Ayala DE, Ucieda R, Hermida RC. Chronotherapy with low-dose aspirin for prevention of complications in pregnancy. Chronobiol Int 2013; 30:260-79.

16. Syngelaki A, Pergament E, Homfray T, Akolekar R, Nicolaides KH. Replacing the combined test by cell-free DNA testing in screening for trisomies 21, 18 and 13. Fetal Diagn Ther 2014; 35:174-84. 